\title{
Jeffery Nicholas, Reason, Tradition and the Good. MacIntyre's Tradition Constituted Reason and Frankfurt School Critical Theory (Indiana: University of Notre Dame Press, 2012)
}

\begin{abstract}
Lia Mela
Democritus University of Thrace

Jeffery Nicholas differentiates between objective reason as a practice of evaluation that provides justification and critique and subjective rationality as a subspecies of reason limited to means-ends forms of reasoning. He believes that modern crisis is a crisis of reason due to the dominant form of reason in modernity, i.e., subjective rationality. Nicholas aspires to develop a substantive form of reason to base a critical theory of society aimed at human emancipation in the spirit of the Frankfurt School. The most interesting part of this effort is that although Nicholas thinks that Habermas's theory of procedural and situated communicative rationality is an initial step towards a substantive conception of reason, he recognizes the limitations of formalism in this conception and argues that the requisite terms provides MacIntyre's theory of tradition-constituted and tradition-constitutive reason. The mediating figure in this project is Charles Taylor, whose critique, first, is used against Habermas and, then, his Gadamerian idea of the "fusion of horizons" is adopted in order to expand MacIntyre’s theory.
\end{abstract}

Keywords: modernity, reason, tradition, good, Frankfurt School, MacIntyre, Taylor

\section{Introduction}

Jeffery Nicholas in his book Reason, Tradition and the Good. MacIntyre's Tradition Constituted Reason and Frankfurt School Critical Theory focuses on contemporary Western civilization's inability to evaluate ends due to the dominant form of reason in modernity, i.e., subjective rationality. In this light, modern crisis is a crisis of reason. Nicholas aspires to develop a substantive form of reason to base a critical theory of society aimed at human emancipation in the spirit of the Frankfurt School. The most interesting part of this effort is that although Nicholas thinks that Habermas's theory of procedural and situated communicative rationality is an initial step towards a substantive conception of reason, he recognizes the limitations of formalism in this conception and argues that the requisite terms provides MacIntyre's theory of tradition-constituted and tradition-constitutive reason. The mediating figure in this project is Charles Taylor, whose critique, first, is used against Habermas and, then, his Gadamerian idea of the "fusion of horizons" is adopted in order to expand MacIntyre's theory.

Lia Mela, assistant professor, Department of Social Administration and Political Science, Democritus University of Thrace, Greece; main research field: Political Philosophy and Moral Philosophy. Email: liamela@yahoo.com. 


\section{Endorsing the Frankfurt School Critique of Reason}

Nicholas tries to connect early Frankfurt School's version of Marxism with MacIntyre's version of Thomistic Aristotelianism. He differentiates between objective (substantive) reason as a practice of evaluation that provides justification and critique and subjective rationality as a subspecies of reason limited to means-ends forms of reasoning. Nicholas argues for a substantive reason that is a form of reason that has the ability to evaluate ends and forms of reasoning in order to base rational argumentation on matters of the good life. Substantive reason is formed by a tradition's conception of the good.

In the first chapter, Nicholas endorses early Frankfurt School's critique of Enlightenment. ${ }^{1}$ Enlightenment Project, a project traced back to Odyssey, fails to bring about freedom as promised, because of its reliance on subjective rationality in the form of scientific reasoning. Instead of freedom, a system of domination, which involves reification of both human beings and nature, emerges. Enlightenment thought fails to emancipate humanity, because it is formed by the desire to dominate nature. In this process of demystification, the subject appears as ordered and stands against nature both external and internal which is objectified as something chaotic outside the subject. The human subject masters nature, but it loses meaningfulness itself, because it can no longer refer to an objective order of all existence were it finds its place and gains purpose nor can it find meaning in itself because as reason distances itself from nature whilst nature is conceived as an object of control, humanity itself becomes just another object of control.

Objective reason refers to an objective innate in the world order outside the individual mind to which it reconciles the individual beings and in reference to which the agent can judge the actions and goals of both individuals and society and give reasons when asked. Objective reason is substantive, which means it requires specific forms of action that reflect this broader order. Subjective rationality denies such an order reducing truth to success. It consists in formal and instrumental aspects of reasoning that can neither posit nor evaluate substantive ends apart from the goal of self-preservation which is rendered possible through the systematization of society in calculable terms.

Subjective rationality is: (a) Formal (2012, 38-41): devoid of content and thus incapable of judging ends as worthwhile in themselves apart from subjective interests and desires since there is no reference to a higher order. Ends are not and cannot be evaluated; they only need to satisfy the requisite formal procedures. (b) Instrumental (2012, 41-45): because reason lost all content related to an objective order, it is reduced to an instrument that allows for the efficient pursuit of any given subjective desires or ends regardless of their content. Because of its inability to judge ends, subjective rationality becomes slave of any ends and in the end it enslaves humanity. As self-interest becomes dominant in society, society itself is justified insofar it serves individual interests.

Enlightenment becomes totalitarian as the qualitative aspects are removed remaining the quantitative aspects that are calculable and thus controllable. Humanity's concern for domination of both humanity and nature is increased. But, considering that meaning and essence are removed, even the needed for liberal capitalism minimum beliefs connected with freedom cannot be sustained. The background of these values is compartmentalized, because they cannot be associated to an objective reality and they appear as just another subjective preference. Although subjective rationality is adopted to lead to Enlightenment, it loses its power of critique and thus it cannot motivate world changing, hence the failure of the Enlightenment's Project.

Subjective rationality and objective reason are the two poles of an antithesis. Horkheimer, argues Nicholas, 
has not abandoned the Enlightenment Project. In Hegelian lines, he requires the dialectical synthesis of reason in its subjective and objective aspects to develop a form of autonomous reason. He does not want to reverse history in order to revive the premodern past of objective ontologies and forms of life. Although Horkheimer thinks that objective rationality is necessary for emancipation, he is worried of its tendency to use oppression to enforce conformity and support hierarchical forms of organization and systems of social domination which are supposed to reflect the order of the universe. Objective reason points to a higher order, according to which individual and social ends can be evaluated, but it proves oppressive, because it establishes its truth as universal and leaves no room for self-reflection.

In this light, the transition to subjective rationality is necessary for emancipation. Therefore, the way out of the crisis is not to replace the subjective with objective aspect of reason, but rather to reconcile them for humanitarian ends. Objective ontologies are defeated by subjective rationality, but in the process, according to Nicholas, subjective rationality has become itself an objective ontology. The ideal of progress has lost its humanistic target: the fulfillment of person. In this context, the aim of critical theory is to escape the tendency to conformism resulting from the authority of the scientific dogma which precludes reflection on science.

The second chapter concerns Habermas's theory of communicative action, focusing on the passage from the modern paradigm of consciousness to a paradigm of intersubjectivity based on the philosophy of language. ${ }^{2}$ Habermas wants to keep the promise of Enlightenment and deal with early Frankfurt School's pessimism. He intends to continue the project of modernity and defend it against its premodern, antimodern, and postmodern opponents. ${ }^{3}$ Although Nicholas recognizes in Habermas's theory of communicative action a first step to the right direction, he concludes that in the end it proves inadequate and that we have to move from philosophy of language to a philosophy of tradition as it is found in MacIntyre's philosophy.

Habermas focuses on the formal universal features of language that underlie everyday communication oriented to reach understanding, when people communicate in order to achieve a valid agreement. Intersubjectivity is the basis of mutual and constraint-free understanding. As illustrated by Nicholas (2012, 63-64), communicative rationality is a mode of dealing with validity claims that is practised by participants that (a) all use the same linguistic expressions in the same way; (b) no relevant opinions are suppressed or excluded; (c) no force is exerted except that of the better argument; (d) everyone is motivated by the desire for truth; (e) no validity claim is exempt from critical evaluation.

Habermas presupposes the differentiation of rationality spheres-scientific, legal and moral, aesthetic - and the universal features of language. He speaks from a postmetaphysical (antifoundationalist) point of view, arguing that ideology critique requires the removal of all metaphysic elements from rationality spheres. The differentiation between rationality spheres is the seal of modernity, but, under this new conception of reason, the different spheres of rationality are interconnected. Each sphere has its own topics, logic, and procedures and although in each sphere issues that arise in the other two spheres might enter in, they do not distort the logic or the procedures of the primary sphere which remains dominant. This mediation leaves room for a critical theory of society.

For objectivist ontologies, either reason transcends space and time because it is found in the structure of the world or the world is given structure by reason itself. For Habermas, procedural rationality is not abstract but situated within space and time and it is found within a given rationality sphere. It is content-dependent, because it is raised here and now, and yet transcendent, because validity claims transcend spaces and times, inasmuch we can distinguish between what is true/good/right in all spaces and times and what is true/good/right 
for the members of the community.

The theory of communicative action is a formal-pragmatic theory of language oriented to reach understanding. Communicative rationality has no content; it rests on formally defined processes of argumentation. For Habermas, certain concepts, such as truth, rationality, and justification, play the same role between different linguistic communities, although they are interpreted and applied differently. So the potential of universalism is grounded on the formal characteristics of language and from this point of view Habermas maintains that universal rationality does not refer to the content of a claim, but it is based on the procedural nature of his formal pragmatics, the way we arrive at that claim.

The universal features of language can provide a ground for rational universal ethics that can cope with the pluralism of different forms of life, because it renders translation possible and serves the humanitarian project. For Habermas, reason is the raising and defending of validity claims. When people interact in communicative action, they raise intersubjectively criticisable validity claims that are not claims based on egocentric calculations of success, which they try to impose to others, but claims they are willing to defend as valid through open argumentation and others can accept or reject on a rational basis. This rational background of communicatively achieved agreement can serve as a basis for the critical power of practical reasoning, because it enables the critique of validity claims that rest on power relationships for their truth. Intersubjectivity serves as a ground for freedom and reconciliation, because in asking and giving reasons for their validity claims in an open dialogue aiming at understanding it is presupposed equality and freedom between the participants.

Early Frankfurt School's philosophers believed that the Enlightenment Project failed, because of the dominance of subjective rationality. They outlined a program for emancipatory reason, which Nicholas endorses and hopes to continue. He believes that Habermas cannot answer the need for a substantive reason and adopt Charles Taylor's critique (1991, 71ff.). ${ }^{4}$ First, Habermas's theory is a critique of instrumental rationality from the perspective of formal rationality. He focuses on subjective rationality, but he does not recognize that subjective rationality includes both instrumental and formal rationality which share the same inability to evaluate ends. Second, Habermas's theory incorporates hidden substantive values, such as freedom and equality, within the theory of communicative rationality that undermine its formal character.

In this light, Habermas's theory of communicative rationality reflects Kantian formalism in its effort to determine the good life not in terms of its contents, as a form of life to be realized, but in terms of the rational procedure adopted to decide what to do. For Habermas, questions of justice have priority over questions of the good life which implies neutrality concerning conceptions of the good and the differentiation of rationality spheres. However, formal rationality cannot justify or motivate action; for this we need, in Taylor's terminology, "strong evaluations;" we need to turn to substantive ethics in order to determine a (substantial) conception of what constitutes the good life.

Taylor points out that Habermas's theory, just like other theories of the priority of right, presupposes a theory of the good. Rational understanding, in Habermas's case, is part of a conception of the good that weights reasonableness reaching understanding above other values. From this point of view, questions of morality, justice, and the good intertwine and cannot be separated. In order to have moral bearing, any concept of rationality must be linked to a particular vision of the good. This is why Taylor believes that Habermas's theory is too formal to justify his morality. Procedural ethics can gain moral force only if the language users already abide by the strong background evaluations that underlie the universal characteristics of language that is a conception of free and equal human beings who aim at reaching understanding on a rational basis. 
Nicholas finds Habermas's proposal of formal rationality inadequate, because it cannot evaluate ends. Following Taylor's critique, he argues that the aims of a critical theory of society presuppose that questions of justice and the good life bear on a substantive worldview, a form of life evaluated as worthwhile for everybody. This project requires, for Nicholas, as a moral bearing of the conception of reason, a notion of tradition and this makes him turn, in chapter three, to MacIntyre's historicized conception of reason. Reason is embedded in tradition and obtains content from its conception of the good.

\section{Towards a Substantive Form of Reason}

Nicholas draws attention to the similarities between Horkheimer and MacIntyre (2012, 88-92) arguing that MacIntyre's views about Frankfurt School are dismissive (2012, 85). He emphasizes that Alasdair MacIntyre, as before him the Frankfurt School Critical Theorists, criticizes modernity for its reliance on subjective rationality and its subsequent inability to evaluate ends and stress the need for a substantive form of reason capable of moral evaluations of ends, which is susceptible to rational scrutiny. Nicholas believes that the required objective conception of reason can be found in MacIntyre's tradition constituted and constitutive reason. ${ }^{5}$

So Nicholas aims at a conception of substantive reason which interconnects reason, tradition, and the good and enables people to evaluate different forms of life. His main purpose is to clarify the nature of this tie as a basis for the ability to make reasonable judgments about ends. In his effort, first, he focuses on moral traditions not to traditions of moral enquiry. Second, he argues that there is a stronger connection between reason and the good than what MacIntyre envisages, which proves essential for a critical theory of society. Third, he proposes Taylor's interpretation of the idea of the "fusion of horizons" as a way to expand MacIntyre's theory of epistemological crisis on matters of intercultural comparisons.

Nicholas seeks to appropriate MacIntyre's theory of tradition constituted and constitutive reason in order to articulate a theory of reason to ground a critical theory of society aimed to emancipation. He refers to MacIntyre's view that the struggle against the exercises of power is possible only through appeal to reason, and connects it with Frankfurt School's view that associates reason with emancipation that is a substantive conception of reason which allows individuals and society to examine their ends and leads to self-reflection, to an examined life worth living. The evaluation of ends is possible by reference to an order of goods provided by tradition.

Nicholas believes that for the aims of a critical theory of society, it is required a substantive conception of reason, which is discussed in chapter four. Substantive reason is connected to a particular tradition and shares its commitments. It consists in standards and exemplars of reasoning used in the giving of and asking for reasons including reason's self-evaluation. He defines substantive reason as a set of social practices that involve the asking for and giving of reasons, the evaluation of those reasons and the asking for and giving of such evaluation, and, importantly, the evaluation of the good. It comprises thinking about and acting on the set of standards and beliefs of a particular social order (2012, 10; 82; 118).

What is the relationship between reason, good, and emancipation? MacIntyre focuses on contemporary society's silence about ends and he develops his theory as a critique of emotivism, i.e., the idea that moral statements are nothing but expressions of preferences, feelings, or desires. In this way, the distinction between manipulative and not manipulative relations disappears, because others are not treated as ends in themselves, when they are not offered good reasons for acting susceptible to rational evaluation, but as means to be 
influenced on emotional, rather than rational, basis for one's own purposes.

According to Nicholas, the significant point that MacIntyre understands, and in this way outweighs Horkheimer, is that reason, even in the form of subjective rationality, is substantive; that subjective rationality is also a particular kind of reason with content: The negation to judge ends is the particular way of life of modernity, which presupposes the compartmentalization of the self, the forum as a public arena for the expression of preferences and market as the dominant institution. Effectiveness is the good for modernity and this assumption leads to greater oppression. The failure of Enlightenment's Project to bring about emancipation is assigned to subjective rationality and flows from the separation of evaluative from reason ability (2012, 152-3).

MacIntyre maintains that although different languages may share some universal features, they remain incommensurable. He differentiates between cosmology laden (traditional) and universal (modern) languages. The language of modernity defines itself apart of any commitments to tradition and in this way loses its ability to appeal to standards of reason and rational justification, because these standards can find a place only within a tradition. Since the modern individual has conflicting desires and no commitments, confronting alternative ways of life from a standpoint external to them all, he has no grounds for rational choice between them and so his choice becomes a matter of individual preference, hence the dominance of subjective rationality. The modern individual can determine the means necessary to satisfy a particular end but she cannot adjudicate between different ends. Consequently, the evaluation of the good lies beyond the scope of reason. Human beings cannot choose reasonably from a standpoint independent from their way of life that is in detachment from their social context within which goods are ordered and rationality is possible. That is why liberal society, bound to neutrality concerning the conceptions of the good, deprives its members from the context to reason. Liberal society cannot provide reasons for its substantive commitments.

Reason consists in a set of beliefs and standards found within traditions of enquiry that is socially embedded arguments extended in history over fundamental agreements with insiders and outsiders. Nicholas claims that MacIntyre acknowledges the historicity of the good, but not the interdependency of reason and the good (2012, 123). He holds a broader than MacIntyre's concept of tradition as the fundamental unifying concept which allows for the understanding of the relationship between reason, cosmologies, symbolic generalizations, and ways of life (2012, 127ff.). It also includes a view of humanity's relationships to itself and to the nature based on this broader view of the cosmos. So it is a conception of human nature that underlies the all effort and defines the good life.

Reason, for MacIntyre, is tradition-constituted and tradition constitutive. From this point of view, reason is a self-referential reflective activity that enables critique. We use the faculty of reason to judge, but also reason is used to judge the constructions of reason which means that the faculty of reason enables self-critique. Usually it is attached great importance to the tradition-constituted and it is overlooked the tradition-constitutive nature of reason in MacIntyre's philosophy. I think that this is the cause of many untenable accusations for relativism and furthermore for conservatism against MacIntyre and that Nicholas's book helps to place the issue in a more appropriate basis. It is this second aspect of reason that serves the purposes of a critical theory of society. Nicholas defines as its telos emancipatory substantive reason. He argues that substantive reason and substantive good are interdependent: It is the conception of the good that gives substance to reason and provides reason with an order of the good, which enables the needed for a critical theory of society evaluation of ends both on individual and collective level. Therefore, critique itself proves immanent in tradition. Only 
substantive reason, because it has itself content derived from a tradition's conception of the good, is capable of judging society and its relations with other societies. Hence, reason is embedded in a society and so is critical theory.

Traditions are differentiated according to their standards of reason and their conceptions of the good: (a) Although there can be agreement on a formal definition of the good as the choiceworthy, the substantive conception of the good varies and proves incommensurable between different traditions, because it is defined in terms of the tradition's conception of human nature. This conception is part of the tradition's conception of the cosmos and nothing meaningful can be said from "a view from nowhere;" (b) although traditions share some form of minimal rationality, they lack any substantive set of standards of justification to evaluate rival values and first principles. That is why in modernity the discussion of moral issues remains beyond the limits of reason, because the participants do not share substantive standards of reason and exemplars of reasoning to understand different ways of life and adjudicate between different systems of values.

Nicholas has to address the unwillingness of MacIntyre to recognize a universal conception of the good and reason. The obvious danger is relativism, a danger Nicholas confronts in chapter five. One thing is to maintain that different traditions endorse different beliefs and values, incompatible ways of life and cosmology and another that they hold different conceptions of reason, which is that reason itself is relative to tradition. There emerge two problems. One is on the level of intracultural comparisons, which amounts to how a tradition changes within itself, how we are to understand progress in the history of tradition, and how we are to decide between multiple conceptions of the good included in the same tradition. The second problem has to do with intercultural comparisons since evaluation of reason occurs not only within but also between traditions. In the latter case, the problem of relativism proves more difficult and undermines critical theory.

Nicholas thesis is based:

(1) on Richard Bernstein, Beyond Objectivism and Relativism: Science, Hermeneutics and Praxis account of Cartesian anxiety: ${ }^{6}$ We, humans, are in anxiety if as fallible creatures are bereft of universal grounds for our being, our knowledge, and morals and so left in madness. So, either we can find an Archimedean point, a permanent a-historical basis to ground our beliefs or, if we abandon this enterprise, we face darkness. In the second case, we are left with relativism, the belief that fundamental concepts, as reason and truth, can be understood only relative to specific theoretical frameworks, paradigms, conceptual schemes, forms of life, or traditions. Nicholas holds, along with Bernstein, that this is a false dichotomy that makes sense only from a Cartesian point of view. He maintains that although reason is historically and socially embedded, we do not end up in chaos, if we accept that comparison is compatible with difference. According to Nicholas, although substantive reason resides only within incommensurable traditions and so we lack an ultimate a-historical ground for our judgments, we still can evaluate beginning from the grounds available from within our tradition and "learning from" others. In other words, although the basic thesis of relativism is truth, relativism is rejected.

(2) Nicholas follows MacIntyre's Thomistic account of truth as adequacy to reality to argue that it allows for reasonable argumentation within and between traditions as for the "learning from" other traditions and in doing so it escapes relativism by rejecting as false the objectivism/relativism dichotomy. He argues that traditions have to prove adequate in accounting for its members' experience of the world and this adequacy is the criterion for reason and for (apparent) truth. Communication and interaction of the members of a tradition rest on a common understanding of shared beliefs and cosmology, i.e., a schema, by which they interpret the 
world and act within it. But schema can also lead to error; it can lead the individual astray in case that it calls for particular actions while the social context calls for different ones or when the person encounters a plurality of schemata with mutually incompatible accounts.

According to MacIntyre, a tradition experiences an epistemological crisis when it fails to make progress according to its own standards. The crisis can be resolved by the construction of a new narrative which enables its members to understand how they could intelligibly have held their original beliefs, how they could have been misled by them, and why their new account supersedes the former account. In this case, we have a new narrative of the history of the tradition and so there is continuity. But if a tradition cannot resolve its crisis, it has to be abandoned. In this case, if a second tradition can expose how the original tradition fails on grounds acceptable to the original tradition, then the second tradition proves superior.

In the process, the agent makes claims to truth as she explains why one interpretation proves more adequate than another. A theory is considered true insofar as it allows its members to interact within the world in ways not liable to disappointment. In this sense, it is more adequate to the world. Truth is a normative ideal which entails that when an adherent of a tradition makes a claim to truth, he means to make a claim about the world regardless of the particular standpoint from which he makes the claim; that is regardless of his tradition's particular perspective. This means that reason might be constituted by and constitutive of a tradition, but truth, as adequacy to the world, is universal. Truth is the ultimate criterion for the evaluation of tradition-constituted explanations of reality.

At this point, so Nicholas holds (2012, 191), MacIntyre agrees with Habermas. Every tradition (MacIntyre) or every language (Habermas) includes an ability to distinguish between how things seem and how things really are. Because of this distinction, when an agent in a particular tradition or language makes a claim to truth, she is necessarily committed to make a claim as to how things really are, not simply how they seem to be. On this ground, Habermas defends a universal-pragmatics of language, formal rationality, which lacks awareness of its own value commitments, whereas MacIntyre turns to moral realism. Into this light, I think we can reasonably assume that it is required some space for abstraction. In MacIntyre's case, abstraction does not concern the withdrawal to some Archimedean point, but the ability to distinguish between what is true/good/right and what the members of a tradition hold to be true/good/right; between how things are and how they should be. If it can be assumed that the above reflective stance is common among all, or at least among the majority of traditions, then there is room for dialogue. This reflective attitude, familiar to us through the modern worldview, is a conditio sine qua non for a critical theory of society.

Nicholas holds that the theory of substantive reason escapes the objectivism/relativism dichotomy, first, by grounding substantive comparisons of reasonable superiority not on an Archimedean point but within and between rival traditions in their adequacy in explaining our experience of the world and, second, by recognizing not only reason's link to tradition but also its ability to evaluate both the good and the standards of reason in the tradition. This potential of reason is needed for a critical theory of society that aims to criticize unjust social practices of domination and power. Since the case it is not one of formal comparison, which finds just similarities in logic and argumentation, but rather substantive comparison which helps to deal with the crisis, this account can ground a critical theory of society, because it justifies alternative ways of life as better because of more reasonable and true on their substantive standards of reason.

(3) Nicholas maintains that although MacIntyre gives us an account of how intercultural comparisons are possible, he is not clear about how dialogue between different traditions can begin. At this point, Nicholas 
invokes Charles Taylor for second time (2012, 205ff.). ${ }^{7}$ He endorses his Gadamerian idea of "fusion of horizons" as a continuation of MacIntyre's arguments, which emphasizes the idea that traditions can learn from one another in open dialogue and thus can morally advance. The key concept here is partial incommensurability. Nicholas is right in moderating the incommensurability thesis. He argues convincingly that for MacIntyre, different languages or traditions are only partially incommensurable, hence they are not completely incomparable (2012, 178). Nicholas also differentiates between (language) translation and understanding. He holds that traditions are not reducible to languages. Understanding different traditions does not imply translatability.

According to MacIntyre, a tradition recognizes another as superior when that other tradition surpasses it according to the first tradition's own standards of reason that is the second tradition proves acceptable according to standards which the first tradition already accepts. Taylor differs from MacIntyre in believing that it is possible to develop a new language neither theirs nor ours but based on both, pointing at an omega point when all times and cultures can come to a universal, but still open, undistortive horizon for all of them, whereas, for MacIntyre, our understanding of others is always in our terms. Nicholas believes that Taylor's account, due to its hermeneutical background, goes beyond MacIntyre's account in admitting that rival traditions share some basic beliefs or standards of reason.

Nicholas builds on Taylor's ad hominem arguments. These arguments are opposed to the foundationalist form of argument, according to which argumentation must proceed from firmly established principles according to strict logical methods. Ad hominem arguments are used to find a common ground in order to begin dialogue. They are (a) directed toward persons, (b) appealing to premises that both sides already accept and (c) comparative. For Taylor, different practices, traditions, and cultures make sense against a background of a more or less articulated cosmology which can be challenged, prove inadequate and change. This happens when open-minded honest people engage in intercultural comparisons and come to understand that their culture is just one of the many.

There are three forms of ad hominem arguments. In the first form, the members of a tradition compare their tradition to a rival one and find the rival superior, as it happens in MacIntyre's resolution of epistemological crisis. The second form requires a nonsymmetrical explanation of the successes and failures of both theories and proves superior the theory which brings the better explanation. This form corresponds to MacIntyre's account of reasonable transitions between traditions: The new theory must be able to appeal to the standards of the old theory and explain the failures and successes of its predecessors. The third form, which is the commonest form of practical reasoning, refers to traditions which differ too much to permit comparisons. In this latter form, the transition is justified as reasonable on grounds that can be described in terms of error-reducing, such as removing contradictions, overcoming confusions, and recognizing new or ignored until today factors.

Nicholas believes that hermeneutics provides substantive reason with resources that enable intercultural comparisons. Understanding does not presuppose escaping one's own point of view in order to have access either to an Archimedean point or to the other's view from the inside. Our self-understanding, as well the way we understand our tradition, can change, among other reasons, because we meet foreign cultures devoted to different ideas of the good, standards of reason, and ways of life which expand our horizons of understanding and in this way, according to Taylor, we escape ethnocentricism. This form of understanding does not occur in terms of either one tradition or another. As Nicholas argues, following Taylor, the aim is fusion of horizons, not 
escaping horizons (2012, 212). We still remain in our point of view, but encountering other traditions expands and in this way changes our tradition as we try to understand the other tradition and so our point of view before and after the fusion of horizons is different. It also means that different rival traditions can be compared, as they appear as alternative approaches to common human constants.

\section{Conclusion}

To conclude, the problem for both MacIntyre's and Taylor's accounts occurs because they are admitting not only that different traditions endorse different conceptions of the good and ways of life but also different standards of reason and in this second case the possibility of expansion is limited whereas the challenge of relativism becomes more severe. Is it possible to develop inside history a non-foundationalist argument that is an argument that does not rely on absolute ahistorical criteria based on some kind of rigorous scientific-logical method? The rejection of absolute criteria differentiates MacIntyre and Taylor from modern post-enlightenment theories whereas the recognition of the need to have criteria differentiates them from postmodern thinkers. It is cultural traditions that provide the required criteria. Substantive reason can criticize conceptions of the good and beliefs about human nature just because it is ground in a tradition's cosmological and cultural beliefs that constitute the fundament agreements of that tradition.

Nicholas rejects any idea of universal Archimedean point of view neutral between different conceptions of the good and points out that each tradition has its own conception of substantive reason which is constituted and constitutive of its conception of the good in MacIntyrean terms. He admits that he writes from within Thomistic-Aristotelian tradition combined with the Marxist tradition as found in Frankfurt School critical theory. He aims at social critique which grounds itself in tradition and aims at establishing an emancipated just society. Nicholas's proposes a critique based on the Thomistic tradition of natural law and argues that for this purpose it is also required a (broader than that found in Dependent Rational Animals) theory of human nature.

Is it possible such a theory to be developed today? The question is whether Nicholas moves towards an ontologically grounded substantive theory susceptible to worries regarding its oppressive effects and its tendency to enforce conformity from the viewpoint of the Frankfurt School Theorists. Whether, that is, Nicholas's criticism against Habermas in reference to Frankfurt School, namely that he uses formal against instrumental rationality, ignoring that both are part of subjective rationality, might be also applied against him, namely that he endorses an ontological theory against subjective rationality, ignoring that what is needed for a critical theory, at least according to Frankfurt School, is a dialectical synthesis of reason in his subjective and objective forms and not a critique of subjective rationality with the tools provided by an objectivist ontology. Although Nicholas seems aware of the problem, when he pays attention to the danger to suppose that there is a winning game between two world orders and two corresponding forms of reason, one of subjective rationality aimed at effectiveness and one of objective reason aimed at excellence (2012, 90ff.).

In any case, regarding the concept of tradition, Nicholas presents one of the most interesting interpretations of MacIntyre's theory connecting it with the needs of a critical theory of society and from this point of view the present review is intended as part of a tradition. Through the attempted connection with the Frankfurt School, Nicholas not only offers a new way of approaching the philosophy of MacIntyre-the philosopher himself does not associate his work with this prior criticism of Enlightenment-but I think he also paves the way to put in new light other contemporary theories as well, such as Charles Taylor's critique, at least as set out in The Ethics of Authenticity. Nicholas is among the philosophers who attempt to move beyond the 
linguistic turn as it is evidenced in his analysis of cosmology-laden moral traditions. Most importantly, Nicholas aims at a critical theory of society that hopes to reform society in the direction of greater freedom. He aims at a substantive conception of reason that can serve emancipatory purposes and seeks the conditions allowing the criticism against domination and exploitation in contemporary societies rediscovering the forgotten promise of freedom.

The emancipatory promise of the enlightenment cannot be renounced. But it has to be separated from the false pretensions of liberation that MacIntyre points out. If, therefore, we want to maintain this promise, perhaps we have to reject major parts of modernity, the ones that are connected with relations of oppression, manipulation, and alienation, but not the request for freedom. And, although Nicholas's critique at several points seems to be much wider, I believe that the commitment to the emancipatory promise in a sense gives immanent character to this critique. It is a critique against a culture that breaks its promises.

\section{Notes}

1. Nicholas critique is mainly based on two major works: Dialectic of Enlightenment and Eclipse of Reason.

2. As set out in his two-volume work The Theory of Communicative Action.

3. See esp. Habermas, 1997, passim.

4. Taylor, 1991, passim.

5. Nicholas critique is based of course on After Virtue's critique against emotivism. A key concept of his account is that of "epistemological crisis" as set out in Whose Justice? Which Rationality? and Three Rival Versions of Moral Enquiry following MacIntyre's Thomistic turn.

6. Bernstein, 1983, 18.

7. On two basic points: (a) the idea of the "fusion of horizons" (Taylor 1995, 146-64, esp. 151), (b) ad hominem arguments (Taylor 1995, 36; 42ff; 51-56).

\section{Works Cited}

Bernstein, Richard. Beyond Objectivism and Relativism: Science, Hermeneutics and Praxis. Oxford: Blackwell, 1983.

D’ Entreves, Maurizio Pesserin, and Seyla Benhabib. "Modernity: An Unfinished Project.” Habermas and the Unfinished Project of Modernity: Critical Essays on the "Philosophical Discourse of Modernity." Cambridge: MIT Press, 1997. 38-58.

Habermas, Jürgen. "Reason and the Rationalization of Society." The Theory of Communicative Action Vol. 1. Trans. Thomas McCarthy. Boston: Beacon Press, 1984.

---. "Lifeword and System: A Critique of Functionalist Reason.” The Theory of Communicative Action Vol. 2. Trans. Thomas McCarthy. Boston: Beacon Press, 1987.

Horkheimer, Max. Eclipse of Reason. New York: Continuum, 1974.

Horkheimer, Max and Theodor Adorno. Dialectic of Enlightenment. Trans. John Cumming. New York: Continuum, 1994.

MacIntyre, Alasdair. After Virtue: A Study in Moral Theory. London: Duckworth, 1981.

---. Whose Justice? Which Rationality? London: Duckworth, 1988.

---. Three Rival Versions of Moral Enquiry: Encyclopedia, Genealogy, and Tradition. Notre Dame: University of Notre Dame Press, 1990.

---. Dependent Rational Animals. New York: Open Court, 1990.

Nicholas, Jeffery. Reason, Tradition and the Good. MacIntyre's Tradition Constituted Reason and Frankfurt School Critical Theory. Indiana: University of Notre Dame Press, 2012.

Taylor, Charles. "Language and Society.” Eds. Honeth Axel and Hans Joas. Communicative Action: Essays on Jürgen Habermas' "The Theory of Communicative Action.” Trans. Jeremy Gaines and Doris Jones. Cambridge: MIT Press, 1991. 24-35.

---. “Explanation and Practical Reason.” Philosophical Arguments. Cambridge: Harvard University Press, 1995. 34-60. 
---. “Comparison, History and Truth.” Philosophical Arguments. Cambridge: Harvard University Press, 1995. 146-64.

---. The Ethics of Authenticity. Cambridge: Harvard University Press, 2000. 